\title{
CARTA DE SOLOS DA BACIA DO RIBEIRÃo CAMBÉ NA ÁREA URBANO-RURAL DE LONDRINA, PR
}

\author{
GERALDO CÉSAR ROCHA ${ }^{1}$
}

ROCHA, G.C. Carta de solos da bacia do ribeirão Cambé na área urbano-rural de Londrina, PR. Semina:

Ci. Exatas/Tecnológicas, v. 16, n. 4, p. 536-549, dez. 1995.

RESUMO: Foram estudados os solos situados na bacia do ribeirão Cambé, em Londrina, Pr. Essa bacia, pela sua localização, sofre vários tipos de agressão ambiental. Em uma área rural-urbana de aproximadamente $75 \mathrm{~km}^{2}$ foram mapeados cinco tipos de solos: latossolo roxo distrófico (LRd), terra roxa estruturada dístrófica/eutrófica (TRd/e), terra roxa estruturada latossólica distrôfica/eutrófica (TRLd/e), hidromórficos indiscriminados (Hi) e litólico eutrófico (Re). Todos eles possuem elevada acidez, argilas de baixa atividade química e são na maioria solos distróficos. Esses solos estão organizados em dois pedoambientes bem distintos, onde predominam latossolos (pedoambiente 1, a noroeste da área) e litólicos e terras roxas estruturadas (pedoambiente 2, a sudeste da bacia). O pedoambiente 1, de característica urbano-rural, deve ser manejado de acordo principalmente com as feições geotécnicas de seus solos, enquanto o pedoambiente 2, mais rural, deve ser utilizado segundo critérios agronômicos de conservação e aptidão agrícola de seus solos.

PALAVRAS-CHAVE: carta de solos; morfologia e classificação de solos; pedologia ambiental.

\section{INTRODUÇÃO}

O conhecimento da população de solos de uma determinada área é imprescindível para estudos aplicados ao meio ambiente, agricultura e planejamento urbano.

Características específicas de cada tipo de solo como espessura, porosidade, percentagem de argila e relevo, assim como composição e propriedades químicas, são parâmetros importantes para o entendimento e manejo adequado do ambiente natural.

A microbacia hidrográfica do ribeirão Cambé localiza-se predominantemente no Município de Londrina, $\mathrm{PR}$, estando uma pequena parte situada no Município de Cambé. Apresenta área de aproximadamente $75 \mathrm{~km}^{2}$, tendo o ribeirão Cambé nascentes próximas ao trevo da BR 369 e desaguando no ribeirão Três Bocas, após percorrer um trajeto de cerca de $26 \mathrm{~km}$. Engloba parte do núcleo urbano da cidade de Londrina, alimentando os lagos Igapó I, II e III.

Trabalhos de campo do autor evidenciaram que esta bacia está atualmente sujeita a todo tipo de agressão ambiental, sendo utilizada por diversas indústrias para descarga de efluentes, na maioria dos casos sem trata- mento prévio. Existem evidências de lançamento de esgotos domésticos clandestinos nas galerias pluviais do sistema. Observa-se também a deposição de lixo urbano associada à implantação de aterros, sem nenhum controle ambiental. Os recursos hídricos da microbacia tem sido também utilizados para captação de água para uso doméstico e industrial, irrigação e atividades recreativas da população de baixa renda. E devido à sua abrangência, a área da microbacia é o embasamento para a expansão urbana de Londrina, além de sediar atividades rurais diversas.

Todos esses fatos constituem-se em justificativas para a confecção da carta de solos da microbacia do Cambé, objetivo principal desse trabalho, o qual é proposto para subsidiar as ações de planejamento urbanorural para o município de Londrina.

\section{DESCRIÇÃO GERAL DA ÁREA}

\subsection{Localização}

A área de estudo engloba parte do núcleo urbano e uma interface urbano-rural da cidade de Londrina, situados a norte do Estado do Paraná. (Figura 1).

1 - UFJF - Universidade Federal de Juiz de Fora - Departamento de Geociências - Campus Universitário - Juiz de Fora - Minas Gerais Brasil - CEP 36036-330. 


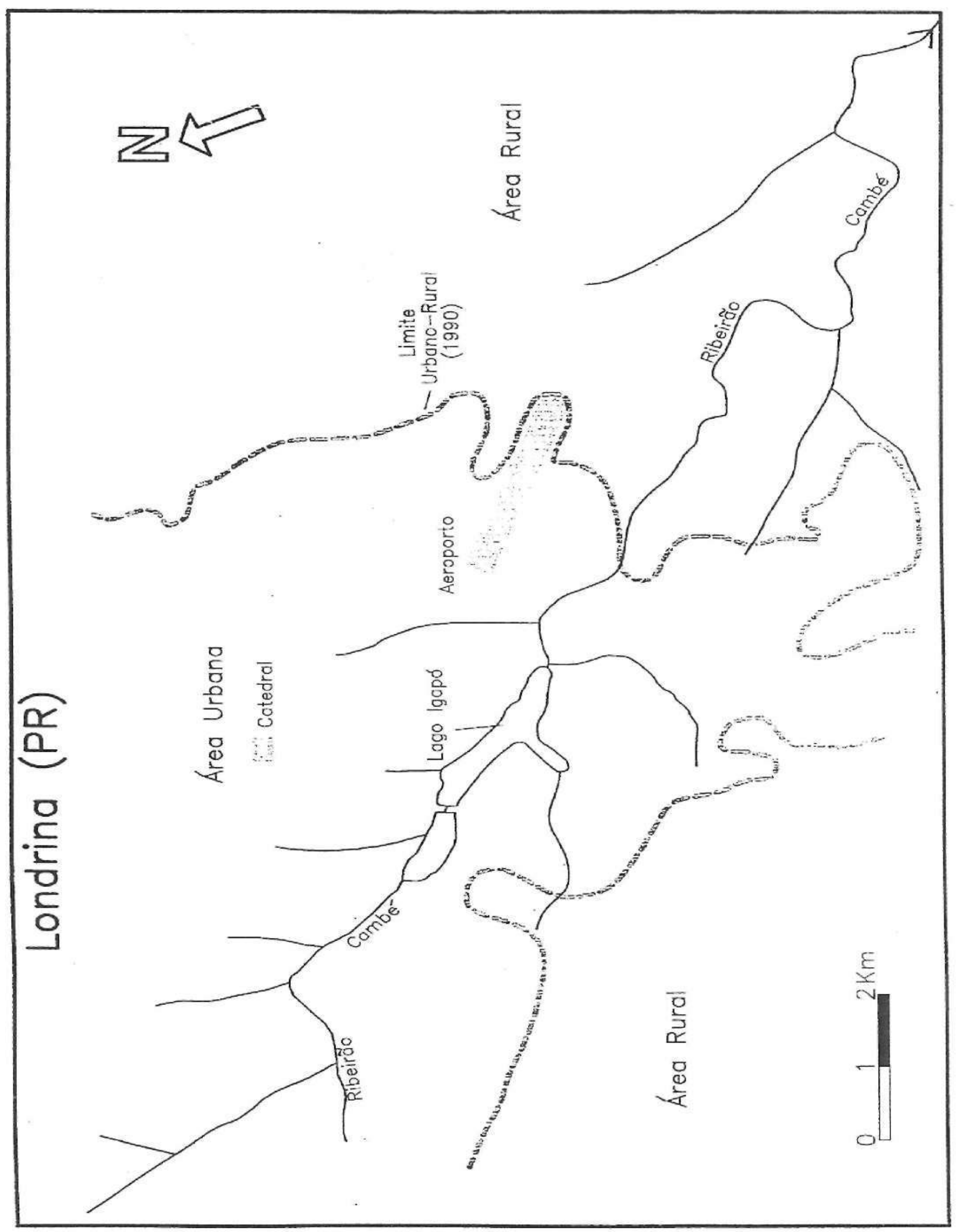

FIGURA 1 - Localização da área de estudo

Semina Ci Exatas/Tecn., v. 16, n. 4, p. 536-649 


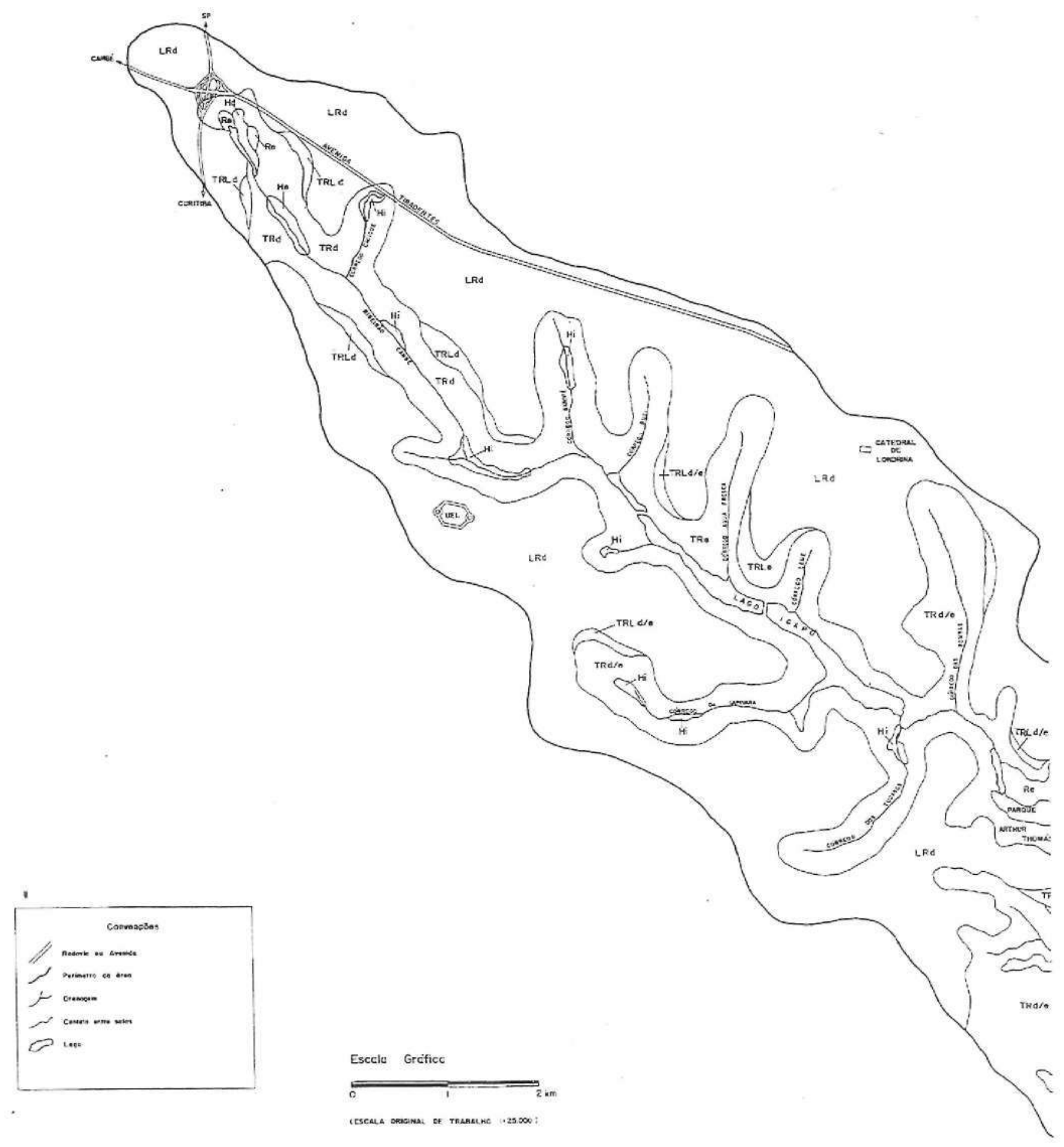



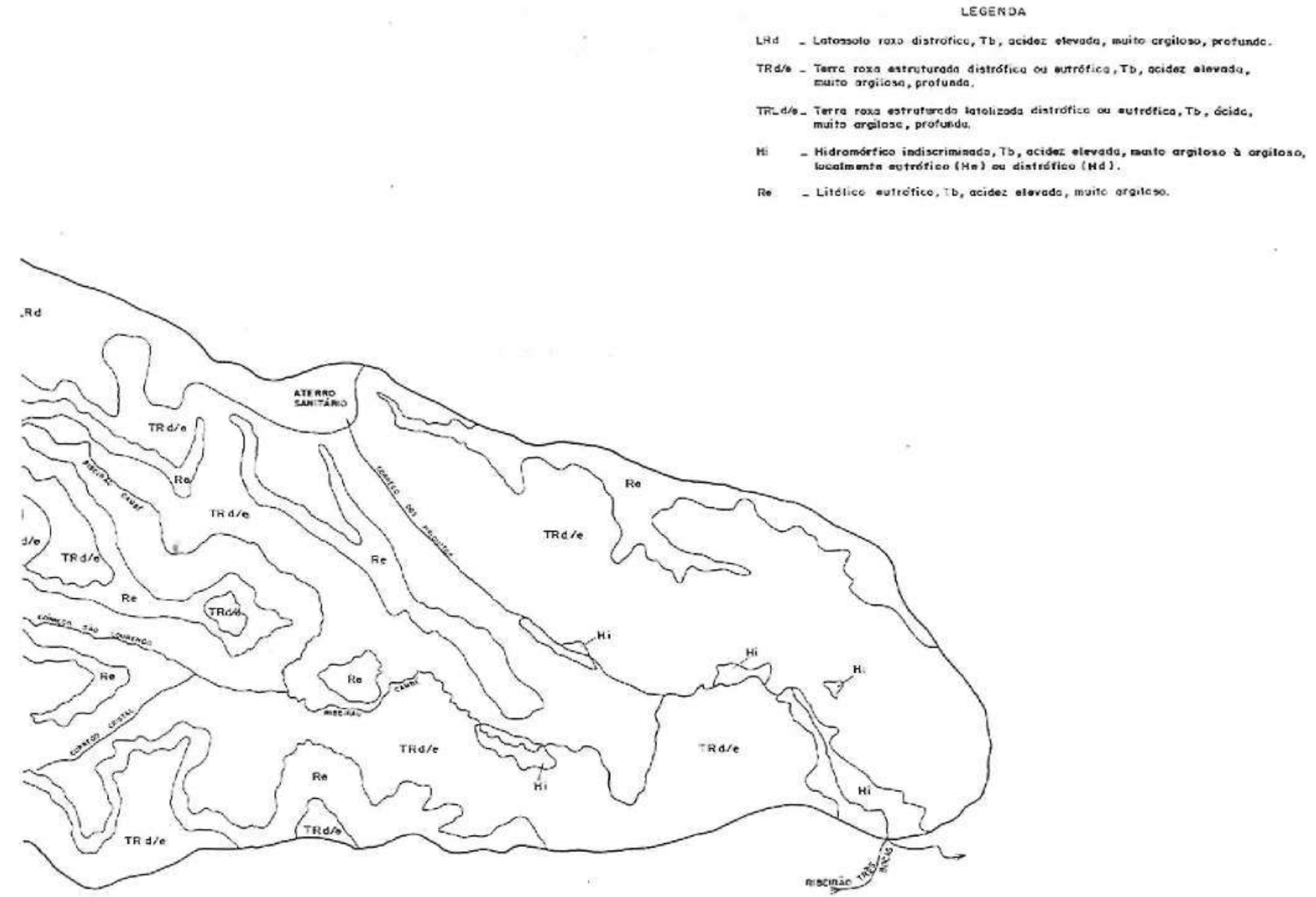

FIGURA 2 - Carta de solos da bacia do ribeirão Cambé 


\subsection{Geologia}

As rochas que ocorrem na área pertencem à For mação Serra Geral e são de idade Triássico/Cretácea, formadas há 120 milhões de anos (PETRI \& FÚLFARO, 1983; POPP, 1981). São rochas ígneas básicas que ocorrem na forma de derrames ou como corpos intrusivos associados.

O vulcanismo não se deu na forma clássica de cones vulcânicos, mas sim através das fissuras ou fraturas das rochas existentes, por onde o magma básico chegou até a superfície. A composição mineralógica dessas rochas é representada principalmente por plagioclásio (labradorita) e piroxênio (augita); ocorrem subordinadamente titano-magnetita, quartzo, apatita, feldspato potássico e minerais opacos.

Os afloramentos rochosos são mais comuns a sudeste da área, provavelmente relacionados ao enxame de diques básicos orientados (diabásicos), que cortam os próprios basaltos existentes. Deve-se mencionar que essas formas litológicas discordantes aumentam em quantidade à medida que se caminha em direção ao sul do município de Londrina, mantendo a mesma orientação NW-SE e influenciando grandemente a conformação do relevo.

\subsection{Relevo}

Geomorfologicamente, a área estudada se situa no Planalto de Guarapuava ou Terceiro Planalto, onde se evidencia, ao lado de pequenos espigões que constituem divisores de águas secundários, apenas suaves colinas e platôs. Não ocorrem linhas de serras elevadas acima do nivel geral do planalto, sendo a paisagem modelada durante o neo-terciário e quaternário, e com declive exibindo um suave abaulamento tectônico em arco aberto para leste (MAACK, 1981). No entanto, as feições diferenciais do relevo local, o qual tem altitudes variando de 390 a 650 metros, permitem subdividi-lo em dois tipos bem característicos: a noroeste da área predomina uma topografia suave ondulada, com topos arredondados, encostas longas e suaves e vales em "U" aberto. Já a sudeste observam-se topos angulosos, com encostas abruptas originando vales fechados em "V".

\subsection{Clima}

Pela classificação de Koppen o clima da área é do tipo Cfa, ou seja, clima subtropical úmido. CORREA et al. (1982) o definem como úmido e mesotérmico, sem deficiência hídrica no inverno. A média anual de chuvas é de $1615 \mathrm{~mm}$, sendo as mesmas bem distribuídas ao longo do ano; entretanto, elas podem causar problemas erosivos sérios quando os solos se encontrarem desprotegidos.

\subsection{Vegetação e Uso do Solo}

A mata original, classificada como floresta tropical subperenifólia (MAACK, 1981; DEMATTÊ, 1973), está praticamente ausente na área estudada, a qual mostra grande parte coberta por pastagem, sendo também comum a vegetação típica das várzeas. A noroeste da área, o núcleo urbano avança através de rodovias, edificações e indústrias (Figura 1), tomando o lugar de remanescentes da vegetação que porventura existam. Já a sudeste predominam áreas rurais, com extensas pastagens nas encostas e topos do relevo.

\section{MATERIAIS E MÉTODOS DE TRABALHO}

\subsection{Materiais}

Utilizaram-se fotografias aéreas em branco e preto na escala 1:25.000 (ITCF - Paraná, 1981) e a planta planialtimétrica da cidade de Londrina na escala 1:20.000 (SUOV - PML, Londrina) como mapas básicos. Como material de apoio foram utilizadas imagens do satélite Landsat TM 22276D em escala 1:50.000, de 25 de março de 1988, em composição colorida das bandas 2 (azul), 5 (verde) e 7 (vermelho); foram obtidas por fotografia do monitor de computador na Universidade de Gottingen (Alemanha).

As ferramentas e instrumentos de campo foram os recomendados por LEMOS \& SANTOS (1982) e SOIL SURVEYSTAFF(1962).

\subsection{Métodos de Campo e Escritório}

O local desta pesquisa abrange a bacia hidrográfica do ribeirão Cambé, área que foi delimitada nas fotografias aéreas e nas imagens de satélites, as quais foram interpretadas para definição de padrões referentes a possíveis tipos diferenciados de solos.

Em seguida todo o local foi percorrido a pé em transversais á linha de drenagem principal, onde os solos foram descritos morfologicamente em cortes de estradas previamente preparados (com altura mínima de 2 metros), pequenas trincheiras (até 1 metro) e tradagem. Além das descrições, os solos foram amostrados em cada horizonte do perfil, material que foi enviado para análises laboratoriais de rotina.

Os resultados analíticos, a morfologia de campo e a localização dos solos na vertente foram usados para se definir as unidades de mapeamento da área, ou seja, utilizaram-se critérios de campo e laboratório. Caracte- 
rísticas específicas foram empregadas nessa definição, listando-se inicialmente aquelas obtidas em campo, como os horizontes diagnósticos, suas profundidades e estruturas, a cor e a drenagem; e as obtidas após análises de laboratório, como a textura, caráter eutrófico/ distrófico, caráter álico, acidez e atividade das argilas. As unidades de mapeamento foram plotadas no mapa básico planialtimétrico.

Após a delimitação dos tipos de solos, fez-se a descrição completa dos perfis representativos de cada unidade de solo, em trincheiras de 2 metros de profundidade. Confeccionou-se em seguida o mapa pedológico da área na escala original 1:25.000 (Figura 2).

\subsection{Métodos de Laboratório}

Para as análises físicas e químicas de rotina, as amostras de solo foram secas ao ar e passadas em peneira de $2 \mathrm{~mm}$, obtendo-se a Terra Fina Seca ao Ar (TFSA). As análises foram realizadas no IAPAR em Londrina, PR.

\subsubsection{Análise Física}

Granulometria: foi empregado o método da pipeta (CAMARGO et al., 1986; MUZILLI, 1978).

\subsubsection{Análises Químicas}

$\mathrm{pH}$ : em $\mathrm{CaCl}_{2} 0,01 \mathrm{M}$

$\mathrm{Ca}, \mathrm{Mg}$ e $\mathrm{Al}$ : em $\mathrm{KCl} 1 \mathrm{~N}$ 1986)

$\mathrm{H}$ e Al: método IAC, a pH 7,0 (CAMARGO et al.,

$\mathrm{K}$ e $\mathrm{P}$ : método de Mehlich

C: método de Walkey e Black

Valor S: somatória de $\mathrm{Ca}, \mathrm{Mg}$ e $\mathrm{K}$

Valor T (CTC): somatória de S com $(\mathrm{H}+\mathrm{Al})$

Valor V: pela fórmula Sx100/T
Saturação em Al: pela fórmula 100Al/A1+S

\section{DESCRIÇÃO DOS SOLOS}

Foram identificadas e mapeadas na área cinco unidades de mapeamento de solos, definidas de acordo com as características citadas e mostradas na Figura 2. Cada unidade ou tipo de solo será descrita a seguir:

\subsection{Latossolo Roxo Distrófico (LRd)}

Este solo ocupa aproximadamente 29 quilômetros quadrados, correspondente a $39 \%$ da área estudada. Dispõe-se nas partes mais elevadas das vertentes, em relevo suave ondulado com declives entre 4 a $8 \%$, nas cotas entre 620 e 630 metros.

Esta unidade agrupa os solos mais intemperizados da área. São solos profundos, muito lixiviados e porosos devido à sua localização nas partes altas e mais planas da topografia, que permite percolação profunda das águas das chuvas em seu perfil. São os solos mais antigos da região (ROCHA, 1990). Apresentam horizonte $B$ latossólico típico com estrutura maciça composta de pequenos agregados, ditos "pó de café", e cor predominante bruno avermelhado escuro (2,5YR3/4).

São solos com elevada acidez, localmente com alta saturação de alumínio (álícos).

Apesar de muito argilosos, suas argilas são de baixa atividade de troca iônica, apresentando também saturação em bases abaixo de 50\% (distróficos).

Em termos físicos, são solos de alta permeabilidade, pouco propensos à erosão. Apesar de muito argilosos, seus minerais de argila se agregam uns aos outros, formando partículas de tamanho areia, as quais entretanto, apresentam boa plasticidade.

No Quadro 1 estão os resultados das análises físicas e químicas deste solo. Em seguida, tem-se as características ambientais e morfológicas do perfil típico desta unidade.

QUADRO 1 - RESULTADOS DE ANÁLISES FÍSICAS E QUÍMICAS DO LATOSSOLO ROXO DISTRÓFICO (LRd)

\begin{tabular}{|c|c|c|c|c|c|c|c|c|c|c|c|c|c|c|c|c|}
\hline \multirow{3}{*}{ Hor } & \multirow{3}{*}{ Prof. } & \multirow{3}{*}{$\underset{\mathrm{CaCl} 2}{\mathrm{pH}}$} & \multirow{3}{*}{$c \%$} & \multirow{3}{*}{ Areia } & \multicolumn{2}{|c|}{ Granul. \% } & \multirow[b]{3}{*}{$\mathrm{Ca}$} & \multicolumn{2}{|c|}{ Trocáveis } & \multirow[b]{3}{*}{$\mathbf{H}$} & \multirow[b]{3}{*}{ Al } & \multicolumn{4}{|c|}{ Valores Calculados } & \multirow{3}{*}{$\begin{array}{c}\mathrm{P} \\
\mathrm{ppm}\end{array}$} \\
\hline & & & & & Silte & Argila & & & & & & mer1 & & $\%$ & & \\
\hline & & & & & & & & Mg & K & & & $\mathbf{s}$ & $T$ & $v$ & Al & \\
\hline Ap & 0.20 & 4,2 & 1,36 & 14 & 12 & 74 & 4,35 & 2.18 & 0,15 & 8,93 & 1.11 & 6,68 & 16,72 & 39,95 & 14,25 & 3,6 \\
\hline$A B$ & $20-40$ & 4,2 & 1,46 & 14 & 13 & 73 & 4,05 & 1.48 & 0,05 & 8.57 & 0,68 & 5,58 & 14,83 & 37,73 & 10,86 & 1,7 \\
\hline$B 2 W$ & $40-1804$ & 4,3 & 1.52 & 17 & 10 & 73 & 4,60 & 0,95 & 0,02 & 8,02 & 0,50 & 5,57 & 34,09 & 39,53 & 8,24 & 2,1 \\
\hline
\end{tabular}


Unidade Latossolo Roxo Distrófico (LRd)

\section{A. DESCRIÇÃO GERAL}

CLASSIFICAÇÃO: Latossolo Roxo Distrófico, Tb, acidez elevada, muito argiloso, relevo suave ondulado.

LOCALIZAÇÃO: $100 \mathrm{~m}$ ao norte da Av. Tiradentes.

SITUAÇÃO, DECLIVE E COBERTURA VEGETAL SOBRE O PERFIL: Trincheira situada no topo da encosta com declive de $8 \%$ e sob cobertura de pasto.

ALTITUDE: 620 metros.

LITOLOGIA: Rochas básicas (basalto).

FORMAÇÃO GEOLÓGICA: Formação Serra Geral.

PERÍODO: Triássico/Cretáceo.

MATERIAL ORIGINÁRIO: Produto de alteração de rochas básicas.

PEDREGOSIDADE: Não pedregosa.

ROCHOSIDADE: Não rochosa.

RELEVO LOCAL: Suave ondulado.

EROSÃO: Laminar moderada.

DRENAGEM: Acentuadamente drenado.

VEGETAÇÃO PRIMÁRIA: Floresta Tropical Subperenifólia.

CLIMA: Cfa (Koppen).

USO ATUAL: Pastagem.

\section{B. DESCRIÇÃO MORFOLÓGICA}

Ap $\quad 0-20 \mathrm{~cm}$, bruno avermelhado escuro (2,5YR3/4, úmido); muito argiloso; fraca pequena a média granular; macio, friável, ligeiramente plástico e ligeiramente pegajoso; transição clara e ondulada.

AB 20-40cm, bruno avermelhado escuro (2,5YR3/4, úmido); muito argiloso; fraca pequena a média blocos subangulares; macro, friável, plástico e pegajoso; transição gradual e ondulada.

B2w 40-180cm+, vermelho escuro (2,5YR3/6, úmido); muito argiloso; fraca média blocos subangulares que se desfaz em forte muito pequena granular com aspecto de maciça porosa; ligeiramente duro, muito friávei; plástico e pegajoso.

RAÍZES: comuns e fasciculares no Ap, diminuindo em profundidade.

OBSERVAÇÕES: Poros comuns e muito pequenos no $A p$ e $A B$ e muitos poros pequenos no Bw. Forte atração magnética no perfil. Descrição feita no mês de março.

\subsection{Terra Roxa Estruturada Distrófica/Eutrófica (TRd/e)}

Esta unidade cobre $23 \mathrm{~km}^{2}$, correspondendo a $31 \%$ da área. Estes solos situam-se predominantemente nas encostas do reievo, ocupando o segundo lugar em área. Estão em altitudes variáveis de 400 a 620 metros sobre relevo ondulado.

Abrangem solos normalmente profundos, apesar de terem sido incluídos nesta unidade algumas associações com Terra Roxa Estruturada Rasa e Pedregosa. São solos que apresentam potencial erosivo devido à existência de horizonte $B$ textural com cerosidade e estrutura bem desenvolvida; o que acontece é que este horizonte se comporta como uma camada semi-permeável, favorecendo a erosão dos horizontes superficiais, já que dificulta a drenagem vertical. Assim, são solos que exigem práticas conservacionistas mais intensas para o uso agrícola, assim como cuidados especiais para os demais usos. O horizonte $B$ textural, quando atingido em trabalhos com máquinas, pode levar à dificuldades de tráfego destas, devido ao seu alto teor em argiias, o que acarreta alta pegajosidade para este material.

Nesta unidade foram agrupados tanto os solos de caráter eutrófico $(\mathrm{V}>50 \%)$, assim como as variedades distróficas $(\mathrm{V}<50 \%)$, devido às mudanças relativamente rápidas que se verificam em sua fertilidade química na paisagem, ou seja, apresentam grande variabilidade espacial química.

Entretanto, todos são solos com argilas de baixa atividade de troca iônica e acidez elevada. São texturalmente argilosos, apresentando em alguns locais concentrações pedregosas ao longo do perfil. No Quadro 2 estão os resultados físicos e químicos obtidos para uma variedade distrófica deste solo, sendo em seguida mostradas as características morfológicas e ambientais do perfil típico.

QUADRO 2 -RESULTADOS DE ANÁLISES FÍSICAS E QUÍMICAS DA TERRA ROXA ESTRUTURADA DISTRÓFICA (TRd)

\begin{tabular}{|c|c|c|c|c|c|c|c|c|c|c|c|c|c|c|c|c|}
\hline \multirow{3}{*}{ Hor } & \multirow{3}{*}{ Prof. } & \multirow{3}{*}{$\underset{\mathrm{CaCl} 2}{\mathrm{pH}}$} & \multirow{3}{*}{$\mathrm{c} \%$} & \multirow{3}{*}{ Areia } & \multicolumn{2}{|c|}{ Granul. \% } & \multirow{3}{*}{$\mathrm{Ca}$} & \multicolumn{3}{|c|}{ Trocáveis } & \multirow{3}{*}{ A] } & \multicolumn{4}{|c|}{ Vatores Catculados } & \multirow{3}{*}{$\stackrel{P}{p p m}$} \\
\hline & & & & & Silte & Argila & & $\mathrm{Ma}$ & $k$ & H & & $m e / 10$ & $0 \mathrm{~g}$ & 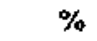 & & \\
\hline & & & & & & & & & & & & $\mathbf{S}$ & $T$ & $v$ & Al & \\
\hline$A$ & $0-12$ & 4,2 & 0.69 & 8 & 6 & 86 & 2,95 & 1,56 & 0,05 & 6,41 & 1,44 & 4,56 & 12,41 & 36,74 & 24,00 & 1,5 \\
\hline$A B$ & $12-40$ & 4,3 & 0,53 & 5 & 7 & 88 & 2,83 & 1,60 & 0,02 & 5,60 & 1,06 & 4,45 & 11,11 & 40,05 & 19,24 & 1,4 \\
\hline $\mathrm{B} 2 \mathrm{t}$ & $40-150+$ & $+4,3$ & 0,39 & 7 & 7 & 86 & 2.83 & 1,65 & 0,07 & 5.22 & 0,92 & 4,55 & 10,69 & 42,56 & 16.82 & 1,9 \\
\hline
\end{tabular}




\section{Unidade Terra Roxa Estruturada Distrófica}

\section{A. DESCRIÇÃO GERAL}

CLASSIFICAÇÃO: Terra Roxa Estruturada Distrófica, $\mathrm{Tb}$, acidez elevada, muito argilosa, relevo ondulado.

LOCALIZAÇÃO: 10 metros ao norte do canal do ribeirão Cambé (margem esquerda), nos fundos da Sociedade Rural do Paraná, em Londrina, PR.

SITUAÇÃO, DECLIVE E COBERTURA VEGETAL SOBRE O PERFIL: Trincheira situada no terço inferior da encosta com declive de $20 \%$ sob cobertura de grama.

ALTITUDE: 605 metros.

LITOLOGIA: Rochas básicas (basalto).

FORMAÇÃO GEOLÓGICA: Formação Serra Geral.

PERÍODO: Triássico/Cretáceo.

MATERIAL ORIGINÁRIO: Produto de alteração de rochas básicas.

RELEVO LOCAL: Ondulado.

EROSÃO: Laminar forte.

DRENAGEM: Bem drenado.

VEGETAÇÃO PRIMÁRIA: Floresta Tropical Subperenifólia.

CLIMA: Cfa (Koppen).

USO ATUAL: Área em pousio.

\section{B. DESCRIÇÃO MORFOLÓGICA}

A $\quad 0-12 \mathrm{~cm}$, bruno avermelhado escuro (2,5YR3/4, úmido); muito argiloso; fraca pequena a média granular; macio, friável, plástico e pegajoso; transição gradual e plana.

$A B \quad 12-40 \mathrm{~cm}$, bruno avermelhado escuro (2,5YR3/4, úmido); muito argiloso; moderada, pequena, blocos subangulares; ligeiramente duro, friável, plástico e pegajoso; transição gradual e plana.
B2t $\quad 40-150 \mathrm{~cm}+$, vermelho escuro (2,5YR3/6, úmido); muito argiloso; forte, média, prismática composta de moderada média, blocos subangulares; cerosidade forte e abundante; ligeiramente duro, plástico e pegajoso. RAÍZES: poucas nos horizontes A e B.

OBSERVAÇÕES: Poros comuns muito pequenos em todo o perfil.

Atração magnética em todo o perfil.

Descrição feita em julho de 1991.

\subsection{Terra Roxa Estruturada Latossólica Distrófica/ Eutrófica (TRLd/e)}

Este solo cobre $15 \mathrm{~km}^{2}$ da área trabalhada correspondendo a $20 \%$ da mesma. Localiza-se no terço superior das encostas, em relevo suave ondulado em torno de $7 \%$ de declividade. A altitude local varia ao redor de 610 metros.

Esta unidade apresenta solos "intergrade" com horizonte $B$ textural bem estruturado e com cerosidade, ã profundidade média de $50 \mathrm{~cm}$, e horizonte B laíossõlico granular e com estrutura "pó-de-café" a $100 \mathrm{~cm}$.

São solos de ocorrência comum na região, (ROCHA, 1986), os quais por sua estruturação diferencial ao longo do perfil, têm como conseqüência uma dinâmica irregular de água, fato importante para seu manejo adequado. Em termos agrícolas, há que se verificar o quanto essa característica vai interferir no espaçamento entre curvas de nível, ou no efetivo impedimento físico para o crescimento das raízes.

Além disso, tratam-se de solos com razoável potencial erosivo, já que apresentam uma camada de espessura em torno de $40 \mathrm{~cm}$, a quai vai modificar a drenagem da água das chuvas ao longo do perfil.

São solos distróficos ou eutróficos, ácidos e com argilas de baixa atividade (Quadro 3). Apresentam classe textural muito argilosa e são profundos. Em seguida é descrito o perfil típico da classe distrófica.

QUADRO 3 - RESULTADOS DE ANÁLISES FÍSICAS E QUÍMICAS DA TERRA ROXA ESTRUTURADA LATOLIZADA DISTRÓFICA (TRLd)

\begin{tabular}{|c|c|c|c|c|c|c|c|c|c|c|c|c|c|c|c|c|}
\hline \multirow{3}{*}{ Hor } & \multirow{3}{*}{ Prof. } & \multirow{3}{*}{$\begin{array}{c}\mathrm{pH} \\
\mathrm{CaCl2}\end{array}$} & \multirow{3}{*}{$\mathrm{C} \%$} & \multicolumn{3}{|c|}{ Granul. \% } & \multicolumn{4}{|c|}{ Trocáveis } & \multirow{3}{*}{ Al } & \multicolumn{4}{|c|}{ Valores Calculados } & \multirow{3}{*}{$\begin{array}{c}P \\
\text { ppm }\end{array}$} \\
\hline & & & & Areia & Silte & Argila & $C \rightarrow$ & & $\mathbf{K}$ & & & me/t & $\lg$ & $\%$ & & \\
\hline & & & & & & & $\mathrm{Ca}$ & Mg & $\mathbf{K}$ & $H$ & & $\mathbf{s}$ & $\mathbf{T}$ & $\mathbf{v}$ & Al & \\
\hline A & $0-20$ & 4.5 & 2,23 & 12 & 13 & 75 & 3,10 & 2,18 & 0,30 & 7,47 & 6,38 & 5,58 & 13,43 & 41,55 & 6,38 & 1,0 \\
\hline B21t & $20 \cdot 60$ & 4.7 & 1.46 & 11 & 13 & 76 & 2,78 & 1.81 & 0.17 & 5,87 & 5,37 & 4,76 & 10,90 & 43,67 & 5,37 & 1,0 \\
\hline $\mathrm{B} 22 \mathrm{~W}$ & $60-180+$ & 4.9 & 0,87 & 8 & 10 & 82 & 2,60 & 1,15 & 0,05 & 4,73 & 1.81 & 3.8 & 8.60 & 44,19 & 1,81 & 1,0 \\
\hline
\end{tabular}




\section{Unidade Terra Roxa Estruturada Latossolizada Distrófica}

\section{A. DESCRIÇÃO GERAL}

CLASSIFICAÇÃO: Terra Roxa Estruturada Latossolizada Distrófica, Tb, ácida, muito argilosa, relevo suave ondulado.

LOCALIZAÇÃO: Encosta leste do vale do Rubi, 200 metros a norte da ligação entre os lagos Igapó I e II.

SITUAÇÃO, DECLIVE E COBERTURA VEGETAL SOBRE O PERFIL: Trincheira situada no terço superior da encosta, com declive de $7 \%$, sob cobertura de pasto.

ALTITUDE: 610 metros.

LITOLOGIA: Rochas básicas (basalto).

FORMAÇÃO GEOLÓGICA: Formação Serra Geral.

PERÍODO: Triássico/Cretáceo.

MATERIAL ORIGINÁRIO: Produto de alteração de rochas básicas.

RELEVO LOCAL: Suave ondulado.

EROSÃO: Laminar ligeira.

VEGETAÇÃO PRIMÁRIA: Floresta Tropical Subperenifólia.

CLIMA: Cfa (Koppen).

USO ATUAL: Pastagem.

\section{B. DESCRIÇÃO MORFOLÓGICA}

A $\quad 0-20 \mathrm{~cm}$, bruno avermelhado escuro $(2,5 \mathrm{YR} 3 / 4$, úmido); muito argiloso; fraca pequena a média granular; macio, friável, ligeiramente plástico e ligeiramente pegajoso; transição clara e ondulada.

B211 20-60cm, vermelho escuro (2,5YR3/6, úmido); muito argiloso; moderada, pequena prismática; cerosidade forte e comum; ligeiramente duro, friável, plástico e pegajoso; transição gradual e irregular.

B22w 60-180cm+, vermelho escuro \{2,5YR3/6, úmido); muito argiloso; fraca média, blocos subangulares que se desfaz em forte muito pequena granular com aspecto de maciça porosa; ligeiramente duro, muito friável, plástico e pegajoso.

RAÍZES: Comuns e fasciculares no A, diminuindo em profundidade.

OBSERVAÇÕES: Poros comuns muito pequenos nos horizontes $A$ e $B 21$ e muitos poros muito pequenos no B22w. Forte atração magnética no perfil. Descrição e amostragem em maio/91.

\subsection{Hidromórficos Indiscriminados (Hi)}

Os solos hidromórficos distribuem-se por $2 \mathrm{~km}^{2} \mathrm{da}$ área estudada, perfazendo $2 \%$ dos solos levantados. No mapa estão designados por $\mathrm{Hi}$, quando não definidos em termos de fertilidade química; He, quando eutróficos ( $\mathrm{V}>50 \%)$, e $\mathrm{Hd}$, quando distróficos $(\mathrm{V}<50 \%)$. Estas unidades encontram-se nas partes mais baixas e planas da topografia, nos fundos dos vales e ao longo da drenagem, em deciives em torno de $3 \%$ e altitudes variando de 580 a 590 metros.

São solos de coloração cinza escura, saturados de água na maior parte do ano, com drenagem deficiente e ambiente químico redutor. A saturação em água às vezes dificulta a abertura de trincheira neste solo, sendo necessário o uso do trado holandês para a amostragem do perfil.

Possuem argilas de baixa reatividade e acidez elevada (Quadro 4). O percentual de argila é menor que dos outros solos da área estudada, sendo a classe textural variável de muito argilosa a argilosa. O horizonte $B$ hidromórfico apresenta estrutura maciça. Este horizonte foi também encontrado em profundidade associado aos solos próximos da linha de drenagem da área.

QUADRO 4 - RESULTADOS DE ANÁLISES FÍSICAS E QUÍMICAS DO HIDROMÓRFICO INDISCRIMINADO EUTRÓFICO (Hi)

\begin{tabular}{|c|c|c|c|c|c|c|c|c|c|c|c|c|c|c|c|c|}
\hline \multirow{3}{*}{ Cam } & \multirow{3}{*}{ Prof. } & \multirow{3}{*}{$\begin{array}{c}\mathbf{p H} \\
\mathrm{CaCl2}\end{array}$} & \multirow{3}{*}{$\mathrm{C} \%$} & \multicolumn{3}{|c|}{ Granul. \% } & \multicolumn{4}{|c|}{ Trocáveis } & \multirow{3}{*}{$\mathbf{A l}$} & \multicolumn{4}{|c|}{ Valores Calculados } & \multirow{3}{*}{$\underset{\text { ppm }}{P}$} \\
\hline & & & & Areia & Sifte & Argila & $\mathrm{Cl}_{3}$ & & & & & $\mathrm{me} / 10$ & & $\%$ & & \\
\hline & & & & & & & Ca & Mg & $\mathbf{K}$ & $\mathbf{H}$ & & $\mathbf{s}$ & $\mathbf{T}$ & $v$ & Al & \\
\hline $1^{2}$ & $0-20$ & 4,7 & 1,40 & 39 & 11 & 50 & 7,73 & 2,22 & 0,12 & 3.75 & 0,0 & 10,07 & 13,82 & 72,87 & 0.0 & 7,6 \\
\hline $2^{\mathbf{a}}$ & $20-65+$ & 4,6 & 1,18 & 35 & 13 & 52 & 6,43 & 1,97 & 0,05 & 3,75 & 0,0 & 8,45 & 12,20 & 69,26 & 0,0 & 9,8 \\
\hline
\end{tabular}




\section{Unidade Hidromórfico indiscriminado Eutrófíco (He)}

\section{A. DESCRIÇÃO GERAL}

CLASSIFICAÇÃO: Hidromórfico Indiscriminado Eutrófico, Tb, acidez elevada, muito argiloso a argiloso, relevo plano.

LOCALIZAÇÃO: Encontro do ribeirão Cambé com ribeirão Três Bocas.

SITUAÇÃO, DECLÍVE E COBERTURA VEGETAL SOBRE O PERFIL: Ponto de observação situado no fundo do vale, com deciive de $2 \%$ e vegetação de gramíneas.

ALTITUDE: 480 metros.

LITOLOGIA: Rochas básicas (basalto).

FORMAÇÂO GEOLÓGICA: Formação Serra Geral.

PERÍODO: Triássico/Cretáceo.

MATERIAL ORIGINÁRIO: Sedimentos inconsolidados.

PEDREGOSIDADE: Ausente.

ROCHOSIDADE: Ausente.

RELEVO LOCAL: Plano.

EROSÃO: Ausente.

DRENAGEM: Mal drenado.

VEGETAÇÃO PRIMÁRIA: Campo de várzea.

CLIMA: Cfa (Koppen).

USO ATUAL: Área com vegetação natural.

\section{B. DESCRIÇÃO MORFOLÓGICA}

$1^{\text {a }}$ Camada $\quad 0-20 \mathrm{~cm}$; bruno acinzentado (2,5YR5/2, seco); argila; moderada pequena granular; ligeiramente duro friável, ligeiramente plástico e ligeiramente pegajoso; transição gradual e piana.

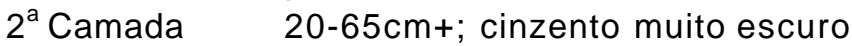
(2,5YR N3/, seco); argila; maciça; ligeiramente duro firme, ligeiramente plástico e ligeiramente pegajoso.

RAÍZES: Abundantes e fasciculares na $1^{\text {a }}$ camada.

OBSERVAÇÕES: Sem poros visíveis no perfil. Descrição feita em abril/91.

\subsection{LITÓLICO EUTRÓFICO (Re)}

Este solo engloba $6 \mathrm{~km}^{2}$, o que representa $8 \%$ da área mapeada. Locaiiza-se principalmente nas meiasencostas das áreas a sudeste da bacia. Está em altitudes próximas a 590 metros, em relevo forte ondulado a ondulado.

São solos rasos, com seqüência de horizontes $A$ / $C$ ou $A / R$, isto é, não apresentam o horizonte $B$ em profundidade. $\mathrm{Na}$ área de ocorrência desta unidade é comum a presença de blocos e matacões de basalto em alteração na superfície dos solos, sendo que a rocha fresca encontra-se aflorante ou próxima à superfície do terreno.

Como as demais unidades que ocorrem na área, estes solos possuem argilas de baixa atividade e acidez elevada (Quadro 5). Entretanto são eutróficos, com saturação de bases acima de $50 \%$.

QUADRO 5 - RESULTADOS DE ANÁLISES FÍSICAS E QUÍMICAS DO LITÓLICO EUTRÓFICO (Re)

\begin{tabular}{|c|c|c|c|c|c|c|c|c|c|c|c|c|c|c|c|c|}
\hline \multirow{3}{*}{ Hor. } & \multirow{3}{*}{ Prof. } & \multirow{3}{*}{$\begin{array}{c}\mathrm{pH} \\
\mathrm{CaCl} 2\end{array}$} & \multirow{3}{*}{$\mathrm{C} \%$} & \multirow{3}{*}{ Areia } & \multicolumn{2}{|c|}{ Granul. \% } & \multirow[b]{3}{*}{$\mathrm{Ca}$} & \multirow{2}{*}{\multicolumn{3}{|c|}{ Trocáveis }} & \multirow[b]{3}{*}{ Al } & \multirow{2}{*}{\multicolumn{4}{|c|}{$\begin{array}{l}\text { Valores Calculados } \\
\mathrm{me} / 100 \mathrm{q}\end{array}$}} & \multirow{3}{*}{$\begin{array}{c}P \\
\text { ppm }\end{array}$} \\
\hline & & & & & Silte & Argila & & & & & & & & & & \\
\hline & & & & & & & & $\mathrm{Mg}$ & K & $\mathrm{H}$ & & $\mathrm{s}$ & $T$ & v & AI & \\
\hline A & 0.30 & 4,6 & 2,37 & 11 & 15 & 74 & 6,40 & 1,69 & 0,12 & 6,94 & 0,29 & 8,21 & 15,44 & 53,17 & 3,41 & 1,5 \\
\hline$R$ & $30-50+$ & - & - & - & - & & - & - & - & - & - & - & - & - & - & - \\
\hline
\end{tabular}

Em seguida mostra-se a caracterização morfológica do perfil modal desta unidade.

Unidade Litólico Eutrófico $(\mathrm{Re})$

\section{A. DESCRIÇÃO GERAL}

CLASSIFICAÇÃO: Litólico Eutrófico, Tb, acidez ele- vada, muito argiloso, relevo forte ondulado.

LOCALIZAÇÃO: Parque Arthur Thomas, 50 metros a leste da represa, na trilha do parque.

SITUAÇÃO, DECLIVE E COBERTURA VEGETAL SOBRE O PERFIL: Trincheira situada no terço inferior da encosta, em deciive de $30 \%$ sob cultura de milho.

ALTITUDE: 590 metros.

LITOLOGIA: Rochas básicas (basalto). 
FORMAÇÃO GEOLÓGICA: Formação Serra Geral.

PERÍODO: Triássico/Cretáceo.

MATERIAL DE ORIGEM: Produto de alteração de rochas básicas.

PEDREGOSIDADE: Pedregosa.

ROCHOSIDADE: Rochosa.

RELEVO LOCAL: Forte ondulado a ondulado.

EROSÃO: Laminar moderada.

DRENAGEM: Bem drenado (horizonte A).

VEGETAÇÃO PRIMÁRIA: Floresta Tropical Subperenifólia.

CLIMA: Cfa (Koppen).

USO ATUAL: Cultivo de milho.

\section{B. DESCRIÇÃO MORFOLÓGICA}

A

0-30cm; bruno avermelhado escuro (2,5YR 3/4, úmido); muito argiloso; moderada pequena granular; duro friável ligeiramente plástico e ligeiramente pegajoso; transição abrupta e plana.

R 30-50cm+; rocha basáltica semi alterada, dura, de cor cinzento escura (2,5Y N4/). Ás vezes apresenta camada de alteração de cor amarelo-brunada (1OYR 6/8), friável.

RAÍZES: Muitas, fasciculares no horizonte A. OBSERVAÇÕES: Poros comuns muito pequenos no A. Descrição e amostragens feitas no mês de abril/91.

\section{OS SISTEMAS PEDOLÓGICOS DA BACIA DO RIBEIRÃO CAMBÉ}

O mapa de solos mostrado na Figura 2 apresenta a distribuição dos solos em área. Uma análise desse mapa sugere que na bacia do ribeirão Cambé existem dois ambientes distintos em termos de predominância de solos, a saber, dois pedoambientes bem nítidos (RESENDE et al., 1988): a noroeste da área predominam latossolos, solos profundos e bem permeáveis, situados em relevo pouco declivoso; já a sudeste da bacia, em topografia ondulada, são mais característicos os solos litólicos e as terras roxas estruturadas. Assim, pode-se falar em dois sistemas pedológicos para a área trabalhada. Observa-se que o mapa pedológico da Figura 2, ao exibir as unidades de solos distribuídas em área, não se mostra suficiente para revelar como essas unidades ou tipos de solos estão se relacionando em profundidade. Uma maneira de evidenciar isso é se tentar a visualização da distribuição espacial dos horizontes ao longo das encostas, como será mostrado na descrição dos pedoambientes. Essa representação não teria objetivo de substituir o mapa pedológico mas sim complementá-lo.

Uma abordagem evolutiva entre os dois sistemas estudados, com base no trabalho de ROCHA (1990) feito na região, e também VOLKOFF (1984-1985) e MONIZ e BUOL (1973), permite se aplicar também na área estudada a hipótese de desmonte de platôs latossólicos. Partindo-se da idéia da existência prévia de uma extensa cobertura latossólica na região, a qual estaria topograficamente na cota dos topos atuais do relevo, os processos geomorfológicos de entalhe da drenagem seriam responsáveis pelo desmonte daquele antigo platô, representado ainda hoje pelo pedoambiente 1 ; haveria 0 desenvolvimento concomitante, nas encostas, de uma estruturação mais desenvolvida nos solos, formando os horizontes B texturais. Essa "superfície" latossólica parcialmente remanescente a noroeste da área, estaria sendo "desmontada" pelo avanço, para montante, dos materiais mais estruturados e menos permeáveis, representados pelo pedoambiente 2. Esses pedoambientes serão mais detalhadamente caracterizados a seguir.

\subsection{Pedoambiente 1}

Fazendo-se cortes transversais nesses dois conjuntos pedológicos, pode-se observar melhor as diferenças desses ambientes e dos horizontes dos solos em profundidade.

A Figura 3 apresenta uma seção segundo a direção leste-oeste, feita a partir do trevo rodoviário até o limite norte da área. Nesta seção estão as características que definem o pedoambiente típico do noroeste da área da bacia. Neste tipo de representação, que tem um propósito complementar ao mapa de solos, procura-se enfatizar a cobertura pedológica como um todo, (ROCHA, 1986), com suas variações internas condicionadas pelas mudanças topográficas aliadas aos processos pedogenéticos; observa-se que nesse corte as unidades de mapeamento não são representadas, pois os solos são vistos como um continuum na paisagem. 


\section{PEDOAMBIENTE 1}
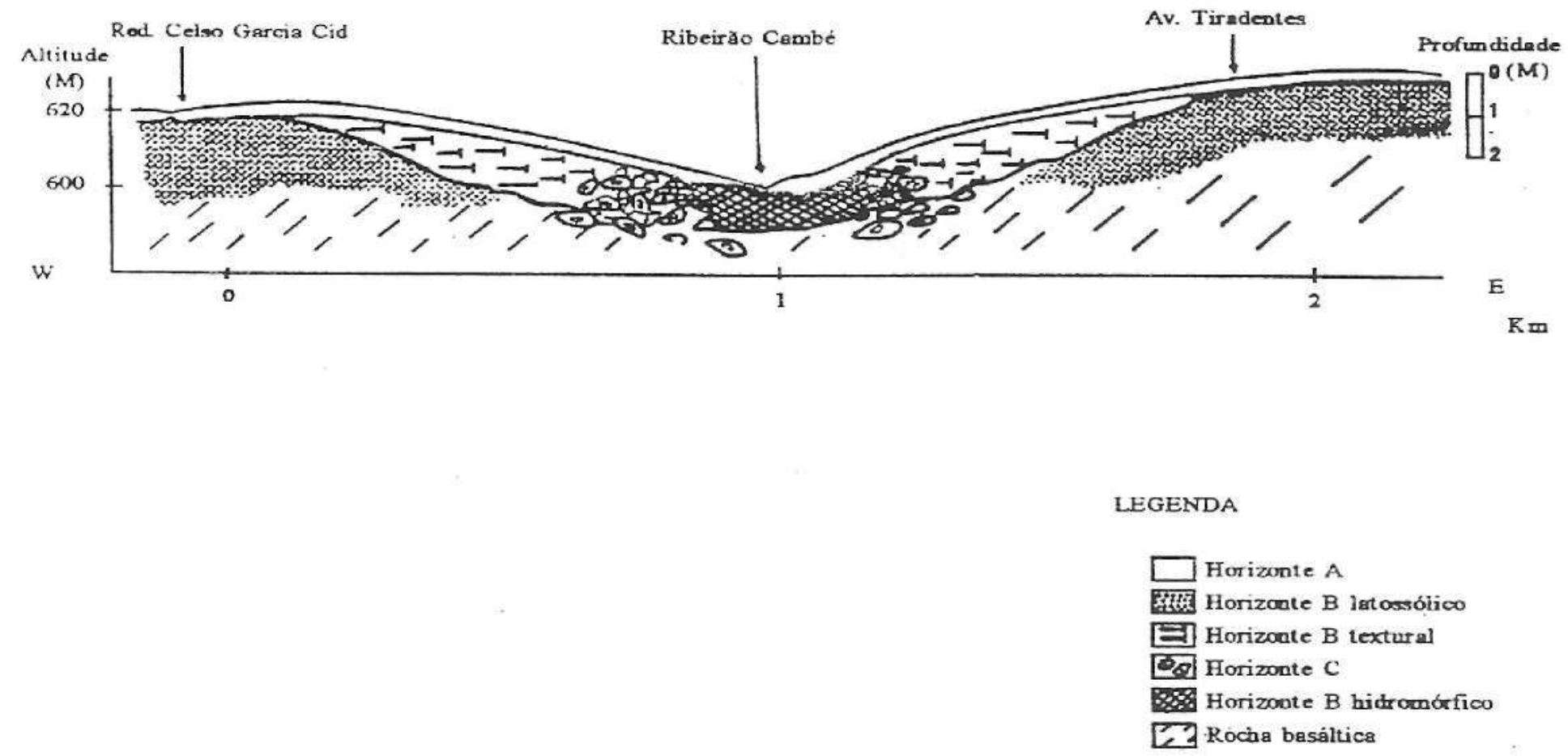

FIGURA 3 - Sistema de solos a noroeste da área (pedoambiente 1)

Evidencia-se dessa maneira feições como espessura, comportamento espacial e características internas dos horizontes, assim como profundidade dos solos, pedregosidade dos solos e hidromorfismo, mostrando também a interrelação entre essas feições.

Observando-se a Figura 3, a partir dos topos do relevo em direção ao vale, nota-se a predominância do material latossólico muito permeável e profundo, nas partes altas e planas da topografia. Esse pedoambiente se caracteriza por encostas longas e suaves, onde na profundidade em direção ao vale o material latossólico é gradualmente substituído por uma cobertura menos permeável e mais estruturada (horizonte B textural). Devese destacar, por exemplo, que ao longo dessa transição a dinâmica vertical da água em profundidade será diferenciada, percoíando mais lentamente através do horizonte $B$ textural e mais rapidamente no $B$ latossólico. Esse fato por si só tem importância geotécnica, já que vai influir na velocidade de drenagem das águas pluviais em áreas com edificações, ou mesmo em locais com fossas sanitárias. E mesmo em áreas com atividades agrícolas, é sabido que a presença de horizontes $B$ texturais pode acentuar processos erosivos caso não se recorra à práticas de conservação do solo.

$\mathrm{Na}$ parte inferior das encostas desse primeiro pedoambiente o solo se enriquece de fragmentos e blo- cos de rocha basáltica semi-alterada, interrompendo a presença do horizonte $\mathrm{B}$ da cobertura pedológica nessa cota. Aqui, então, tem-se solos rasos, litólicos, que apresentam potencial erosivo devido à sua pouca espessura (somente horizonte A). E a camada imediatamente inferior (horizonte $\mathrm{C}$ ), rica em fragmentos intemperizados e bastante fraturada, denota características geotécnicas de baixa resistência para as estruturas de edificações, assim como se mostra inadequada ao uso agrícola intensivo.

Já no fundo do vale, a saturação em água durante a maior parte do ano, condicionando solos hidrornórficos, está relacionada com ambiente químico redutor, além de favorecer características físicas como estruturação maciça e alta plasticidade. São solos que para o uso agrícola ou urbano devem sertotalmente drenados, mas que por outro lado apresentam grande importância ecológica como refúgio e fonte de água para animais nas épocas mais secas do ano. Portanto, são solos que apresentam complexidade química e física que precisam ser observadas no manejo.

\subsection{Pedoambiente 2}

Na Figura 4 tem-se a transeção típica da área situada a sudeste da bacia do Ribeirão Cambé. 


\section{PEDOAMBIENTE 2}

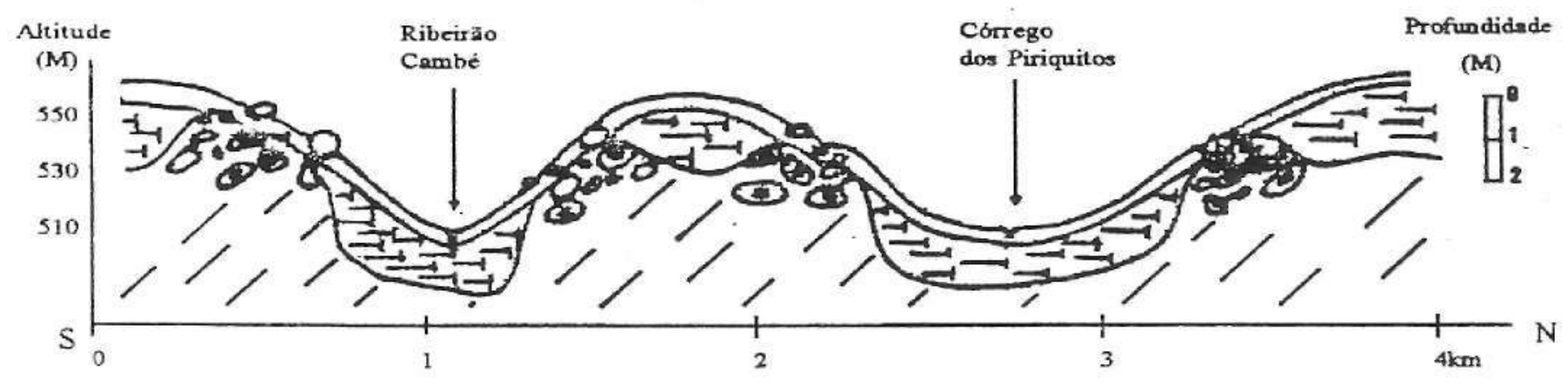

LEGENDA

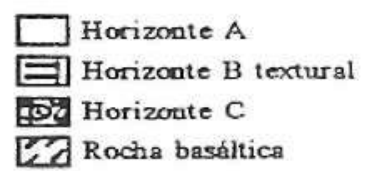

Figura 4 - Sistema de solos a sudeste da área (pedoambiente 2)

Pode-se visualizar um relevo com pendentes curtas e mais declivoso que o pedoambiente 1 , condicionando um sistema de soios formado por terras roxas estruturadas e soios litólicos.

Os topos de relevo e grande parte das encostas estão principalmente ocupados por uma cobertura de material pedológico bem estruturado e pouco permeável (horizonte B textural), a qual se caracteriza por alto potencial erosivo devido à sua baixa capacidade de infiltração da água das chuvas, favorecendo assim o escorrimento superficial. Por tratar-se de uma área rural, o uso desses solos para pastagem por exemplo favoreceria a tendência ao risco erosivo, já que o pisoteio excessivo pelo gado leva à compactação nos primeiros centímetros do solo e conseqüentemente facilita a erosão.

O segundo tipo de cobertura pedológica em importância nesse pedoambiente está representado pelos solos litólicos, os quais ocupam boa parte das encostas da área. Apresentam potencial agrícola devido à sua fertilidade química, mas são também materiais muito passíveis de erosão, devido à sua pouca espessura (somente horizonte A), abundância de fragmentos de rocha e pouca permeabilidade do perfil como um todo. É interessante observar que esses materiais não ocupam o fundo dos vales (como o fazem no pedoambiente 1), mas sim as partes médias das encostas já muito declivosas desse pedoambiente, acentuando o potencial erosivo de toda a cobertura pedoiógica dessa área. Assim, esse segundo pedoambiente, de uso predominantemente rural, deverá receber atenção especial com relação às práticas de conservação e manejo de seus soios.

\section{CONSIDERAÇÕES FINAIS}

A carta de soios ou mapa pedológico não é suficiente para se ter uma visão tridimensional da população de solos estudada. $O$ uso de transeções mostrando o comportamento espacial dos horizontes ao longo das encostas complementa e enriquece o mapa, fornecendo uma visão dos solos de maneira integrada na paisagem, isto é, como uma cobertura pedológica contínua. 
Assim, a separação de dois pedoambientes para a área pesquisada, sugerida na carta de solos, foi bastante evidenciada nas transeções. No pedoambiente 1, de uso principalmente urbano, predomina o iatossoio roxo, seguido pela terra roxa estruturada; são solos com características estruturais distintas, o que se reflete nos seus comportamentos geotécnicos; desse modo, observando-se por exemplo o trevo rodoviário a noroeste da área da bacia, nota-se a sua inadequada localização, na transição entre os solos, o que tem acarretado problemas erosivos no local. É certo que não havia na época da construção o mapa de solos, e provavelmente não se avalia a importância desse; o ideal entretanto seria a construção do trevo somente sobre os latossolos, os quais apresentam características geotécnicas mais favoráveis às obras de engenharia. Por outro lado, a construção do aterro sanitário atual de Londrina já teve apoio na carta de solos, o que levou à sua localização sobre os latossoios mapeados, solos com excelentes características para compactação e impermeabilização. Já para o pedoambiente 2, a predominância de terras roxas estruturadas e solos litólicos em área de uso rural, alerta para a necessidade de práticas conservacionistas rigorosas no uso agrícola, já que tratam-se de solos rasos, como pode ser visto nas transeções, com alto potencial erosivo.

ROCHA, G.C. Soil map of the ribeirão Cambé hidrographic basin at the urban-rural area of Londrina, Paraná state, Brazil. Semina: Ci. Exatas/Tecnológicas, v. 16, n. 4, p. 536-549, Dec. 1995.

ABSTRACT: The soils of the ribeirão Cambé hidrographic basin located at Londrina, PR, Brazil, were studied. An area of $75 \mathrm{~km}^{2}$ shows five soil classes: latossolo roxo distrófico (LRd); terra roxa estruturada distrófica/eutrófica (TRd/e); terra roxa estruturada latossólica eutrófica/distrófica (TRLd/e), hidromórficos (Hi) and litólico eutrófico (Re). All of them have high acidity, small activity clays and are predominantly distrophics. Those soils are organized in two soil systems: the first one, where latossolic soils predominate (pedoenvironment 1, at NW of the area), and the second one, where litholic soils and ultisols occur (pedoenvironment 2, at SE of the basin). The pedoenvironment 1, located at a urbanrural site, must be used in accordance with its geotechnical parameters, while the pedoenvironment 2, basically rural, must be managed following the agronomic capacity of its soils.

KEY-WORDS: soil map; morphology and soil classification; soil systems; environmental pedology.

\section{REFERÊNCIAS BIBLIOGRÁFICAS}

CAMARGO, O.A. (coord.). Métodos de anälise quimica, mineralogica e fisica de solos do instituto Agronômico de Campinas. Campinas, LAC. 94p. 1986.

CORREA, A.R.: GODOY, A. \& BERNARDES, L.R.M. Caracteristicas climáticas de Londrina. Circular IAPAR n. 5. Londrina, IAPAR. 16p. 1982.

DEMATTE, J.L.I. Levantamento detalnado dos solos do estado do Parana. Bol. Técn. 57, v. 1. Londrina, LAPAR (com mapa). 1973.

LEMOS, R.C. \& SANTOS, R.D. Manual de descrição e coleta de solo no campo. Campinas, SBCs. 49 p. 1982.

MAACK, R. Geografia física do estado do Paraná. Rio de Janeiro, José Otimpico. 450p. 1981.

MONIZ, A.C. \& BUOL, S.W. Formation of an oxisol-ultisol transition in São Paulo, Brazil: t. Double water flow model af soil development. S.Sc. Soc. A. J. Madison, 46(6): 1228-1233. 1973.

MUZILLI, O. (coord.) Análise de solos: interpretação e recomendaçāo de calagem e adubação para o estado do Paraná. Circular IAPAR n. 9. Londrina, IAPAR. 49p. 1978.
PETRI, S. \& FÚlfARO, V.J. Geologia do Brasil. Sāo Paulo, EDUSP. 631p. 1983.

POPP, J.H. Geologia Geral. Rio de Janeiro, Livros Técnicos e Científicos. 257p. 1981.

RESENDE, M.: CURI, N. \& SANTANA, D.P. Pedologia e fertilidade do solo: interaçöes e aplicações. Brasilia, MECIESAUPOTAFOS. 84p. 1988.

ROCHA, G.C. Levantamento pedológico detalhado de uma área piloto da bacia do ribeiräo Gafezal, PR. Londrina, CEC/Projeto Cafezal/UEL. Imprensa Universitária. 28p. (com mapa). 1986.

ROCHA, G.C. Caracteristicas e dinâmica de coberturas pedológicas sobre rochas básicas nas regiōes norte e sul do Brasil. ESALQJUSP. 246p. (tese de doutoramento). 1990.

SOIL SURVEY STAFF. Soil survey manual. U.S. Dept. of Agriculture, handbook n. 5. 503p. 1962.

VOLKOFF, B. Organisations régionales de la couverture pédologique du Brésil. Cronologie des différentiations. Cahiers ORSTOM série Pédologie. Paris, XXXI(4): 225-236. 1984-1985. 